\title{
Teoria do caos e gestão da informação: uma integração na complexidade dos negócios e dos sistemas de informação
}

\author{
The chaos theory and information management: \\ integrating the complexities of \\ business and information systems
}

Luiz Henrique CARDOSO ${ }^{1}$

Edmeire Cristina PEREIRA²

\section{R E S U M O}

É abordado o planejamento de sistemas de informação, em seu aspecto teórico, sob a ótica da Teoria do Caos e da Complexidade. Descreve as características dos sistemas físicos, a visão da ciência como sistema fechado e a visão da ciência como sistema aberto. Discute ainda a gestão da informação, tanto frente à complexidade dos sistemas de informação, quanto em suas correlações com o mundo dos negócios, enfatizando a necessidade do profissional da informação de estar apto para planejar o seu trabalho diante do cenário complexo dos negócios.

Palavras-chave: Teoria do caos, complexidade, sistemas de informação, gestão da informação, inovação.

\section{A B S T R A C T}

This paper discusses theoretical aspects of the planning of information systems, under the perspectives of the Chaos Theory and Complexity. It describes the

\footnotetext{
1 Bacharel em Administração e Mestre em Educação. Docente, Setor de Ciências Sociais Aplicadas, Universidade Federal do Paraná. Rua Lotário Meissner, 3400, Jardim Botânico, 80210-170, Curitiba, PR, Brasil. Correspondência para/Correspondence to: L.H. CARDOSO. E-mail: <luizhc_20@hotmail.com>

2 Mestre em Biblioteconomia e Ciências da Informação. Docente, Departamento de Ciência e Gestão da Informação, Universidade Federal do Paraná. Curitiba, PR, Brasil.E-mail: <edmeirepereira@pop.com.br>

Recebido em 7/3/2005 e aceito para publicação em 16/8/2005.
} 
physical systems' characteristics, and the conceptions of Science, either as a closed system or as an open system. This paper also discusses the Management of Information with regard to both, the complexity of information systems, and their correlation with the business world; furthermore, it emphasizes the need for the information professionals to be capable to aptly plan their work, in face of the complex business scenario.

Key words: chaos theory, complexity, information systems, management of information, innovation.

\section{N T R O D U Ç Ã O}

O desenvolvimento da ciência tem sofrido diversas mudanças no decorrer do tempo. $\mathrm{Na}$ visão clássica da ciência - determinista - não existia uma diferença entre o passado e o futuro. Os processos eram reversíveis, pois os dois são intrínsecos ao presente, uma vez que através da observação do estado presente podemos reconstituir o passado. Assim, não existe, nesta visão, um lugar para a história, o novo e, principalmente, para a criatividade.

Com o desenvolvimento da física quântica e da relatividade, a visão clássica da ciência foi modificada radicalmente. Particularmente na Física, os desenvolvimentos resultaram em mudanças significativas em nossa visão de mundo. Com o advento da Relatividade Geral e da Física Quântica uma forma nova de abordar os fenômenos físicos foi introduzida na ciência. Esse novo "olhar" sobre a realidade também modificou a visão empresarial, valorizando o ambiente e suas interconexões. Assim, as informações sobre fornecedores, tecnologia, leis, economia e clientes, são fatores decisivos para que o administrador possa inferir as interconexões existentes neste amplo cenário sistêmico.

Neste contexto, o planejamento de sistemas de informação tornou-se essencial para criar empresas competitivas, administrar corporações globais, implementar produtos e serviços para consumidores cada vez mais exigentes. As organizações são sistemas abertos que interagem num organismo social complexo, através da produção, do consumo, da transformação e da colocação de novos produtos e serviços no mercado e a variável "imprevisibilidade" está presente em todos os negócios. Ignorar este aspecto da moderna administração levará, mais cedo ou mais tarde, à extinção da organização.

\section{Teoria do Caos}

Na década de 60, o meteorologista Edward Lorenz desenvolveu e publicou suas idéias sobre fluxos deterministas não periódicos, que somente muito tempo depois foram descobertas por cientistas e matemáticos, tornando-se então conhecidas como Teoria do Caos. A forma como Lorenz chegou às idéias que levaram à Teoria do Caos é um exemplo de como o acaso está presente e pode ser transformado em inovação científica. Lorenz criou em seu computador um programa simples, tentando, através de alguns elementos essências do tempo atmosférico, prever as condições climáticas futuras. Este programa era utilizado apenas para o estudo das possibilidades de se prever o tempo, e não como uma tentativa definitiva de se conseguir a previsão do tempo "perfeita". O que ele pretendia era verificar se a sua intuição de que o tempo se repetia, revelando padrões conhecidos, estava correta. Ele descobriu que, quando uma linha passava do alto para baixo sem um salto, ocorreria em seguida um salto duplo e percebeu que este tipo de oscilação poderia ser utilizado para previsões 
futuras. No entanto, as repetições nunca eram perfeitamente iguais. Existia realmente um padrão, mas nunca sem alguma pequena alteração. Assim, Lorenz criou um gráfico impresso para melhor "medir" estas variações (LORENZ, 1996).

No inverno de 1961, Lorenz quis examinar detalhadamente uma seqüência. Ao invés de refazer a seqüência, começou pelo meio. Colocou no computador as condições iniciais digitando os números diretamente da impressão anterior e se preparou para esperar a execução do gráfico. Naquela época era um processo demorado e ele decidiu, mais para se livrar do barulho da impressora, tomar um café e voltar mais tarde. Ao voltar, cerca de uma hora depois, ele viu no gráfico algo que mudaria o rumo da ciência. A nova seqüência, que deveria ser a repetição exata da anterior, era diferente da original. As condições de tempo eram tão diferentes que, num espaço de poucos meses, toda a semelhança tinha desaparecido. Ele percebeu que o problema estava nos números que havia digitado. Na memória do computador era possível armazenar seis casas decimais $(0,506127)$ enquanto através do teclado apenas três eram possíveis $(0,506)$. Pensava ele que a diferença, um para mil, não deveria alterar o resultado final. Não foi o que aconteceu. O sistema era sensível às condições iniciais (LORENZ, 1996).

\section{De que caos estamos falando?}

A palavra "caos" está associada a vários significados. Quando se ouve falar em caos, é comum relacioná-lo a uma desordem generalizada ou mesmo a uma grande confusão. Este tipo de caos está diretamente relacionado ao grande número de graus de liberdade existentes em um determinado sistema. Assim, as possibilidades de interferência em um sistema dado são tantas que o seu controle torna-se impossível, instalando-se assim, o "caos".
Aqui, referimo-nos ao caos determinístico, isto é, relativo a sistemas que aparentemente se comportam aleatoriamente, embora sejam determinados por leis muito precisas. O caos determinístico está relacionado ao funcionamento dos sistemas dinâmicos e é caracterizado, basicamente, pela dependência sensível das condições iniciais - o que nos leva, conseqüentemente, à revalorização das pequenas causas. Em contraposição ao caos tradicional, que se observa somente quando muitos graus de liberdade levam à desordem generalizada, o caos determinístico, já pode ser observado a partir de três graus de liberdade (FIEDLER-FERRARA; PRADO, 1994; SCHUSTER, 1995). "Determinístico", neste caso, não se refere à possibilidade de se conhecer com precisão o estado de um sistema ao longo do tempo, mas sim ao fato de ele ser regido por leis precisas. Lorenz (1996, p.20), explica uma seqüência determinística como sendo aquela:

“... na qual apenas uma coisa pode acontecer em seguida; isto é, sua evolução é governada por leis precisas. Logo, a aleatoriedade, no sentido mais amplo, pode ser identificada com ausência de determinismo. Este é o tipo de aleatoriedade que pretendo expressar quando descrevo o caos como algo que parece aleatório".

Lorenz utilizou a expressão "parece aleatório", devido ao fato de existir um outro tipo de ordem - não-linear, a qual foi depois descrita por Bohm (1992, p.160) como sendo a observação das "diferentes similaridades entre as diferenças", como por exemplo, em uma pintura, onde não é possível prever uma parte a partir de outra, embora a pintura seja altamente ordenada. Lorenz (1996, p.21) descreve o caos como:

"[...] um comportamento que é determinístico, ou quase, caso ocorra em um sistema tangível possuindo uma pequena quantidade de aleatoriedade, mas que não aparenta ser determinístico. Isso quer dizer que o estado 
presente determina completamente, ou quase completamente, o futuro, sem parecer fazê-lo" (grifo do autor).

Mas então, por que o sistema não pode ser previsto em sua evolução? A resposta a esta questão é que o sistema é sensível às condições iniciais. Modificações ocorridas no início do processo, e mesmo durante a sua evolução no tempo, ocasionam mudanças que não podem ser previstas inicialmente. Em um sistema linear, qualquer alteração em uma determinada variável, provocará uma mudança proporcional nos instantes subseqüentes, isto é, se uma variável for alterada em, por exemplo, três vezes, a mesma mudança ocorrerá nos instantes seguintes. Desta forma a evolução do sistema no tempo segue uma linha reta, se colocada em um gráfico. Em um sistema não-linear, não ocorre desta forma. Uma alteração de duas vezes, por exemplo, em uma determinada variável do sistema, poderá provocar, nos instantes seguintes, modificações de uma ou de três vezes. No entanto, é bom lembrar que, embora o caos produza não-linearidade, a não-linearidade nem sempre produz caos.

Atualmente, a Teoria do Caos vem sendo aplicada nas mais diversas áreas, como a biologia, medicina, antropologia, meteorologia, economia e agricultura, entre outras, (GLEICK, 1990; LEWIN, 1994), e vem ganhando mais força com o nome de Complexidade.

\section{Os sistemas físicos}

Na física existem três tipos de sistemas: isolado, fechado e aberto. O sistema isolado, como o próprio nome indica, está isolado do meio ambiente, não trocando energia e nem matéria com ele: uma máquina de moto-contínuo é o exemplo ideal disto. Um sistema fechado troca energia, mas não matéria; é algo firmemente controlado, como uma máquina a vapor, onde as variáveis são poucas, os parâmetros prefixados e a previsibilidade alta. O sistema aberto troca ambos, energia e matéria, renovando-se por meio destas trocas. Os sistemas abertos, literalmente "alimentam o fluxo", utilizando este fluxo como a substância para o seu contínuo vir a ser.

O contraste é evidente entre (a) o sistema altamente controlado - fechado - no qual os parâmetros externos formam interações para um fim predeterminado de eficiência, e (b) o sistema flutuante - aberto - no qual as perturbações abastecem o sistema com os meios para as transformações internas; neste, os fins são literalmente integrados aos meios.

\section{A visão da ciência como sistema fechado}

Nesta visão determinista - sistema fechado - não existe uma diferença entre o passado e o futuro. Os processos são reversíveis, pois os dois são intrínsecos ao presente, uma vez que, através da observação do estado presente, podemos reconstituir o passado. Assim, nesta visão não existe um lugar para a história, para o novo e, principalmente, para a criatividade. Esta visão de mundo teve seu impulso no século XVII e suas conseqüências predominam, em maior ou menor grau, até nossos dias.

Esta forma de abordar o mundo alijou do processo o observador em favor do observado. Claramente, este modelo é extremamente racional e analítico, na medida em que tenta reduzir o todo à soma das partes, de uma forma linear. Em suma, é um modelo auto-afirmativo, que fomenta a expansão por meio da competição, na tentativa de obter uma maior quantidade de conhecimento e poder exercer o seu domínio sobre os outros.

Atualmente, as ciências começam a se abrir a outras possibilidades que possam fornecer formas diferentes de se "olhar" o mundo, como a aleatoriedade, a evolução no tempo dos sistemas 
dinâmicos e, principalmente, a auto-organização. Assim, uma mudança nos conceitos se faz necessária: de processos reversíveis deterministas, para processos irreversíveis e indeterminados, uma visão aberta.

\section{A visão da ciência como sistema aberto}

Como escreveu Heisenberg (1987, p.7), "as conseqüências a que a moderna física atômica deu lugar [...] alteraram em muitos lugares deste planeta a visão do mundo que o século XIX nos legou. Elas forçam uma mudança na maneira de pensar e, portanto, interessam a um círculo maior de pessoas". Esta mudança se refere ao advento da teoria da relatividade geral proposta por Einstein e ao desenvolvimento da física quântica. A primeira se relaciona às grandes distâncias - ao infinitamente grande - enquanto a segunda ao espaço microscópico - ao infinitamente pequeno. Através de colisões de alta energia, descobriu-se um número muito grande de novas partículas. O modelo de átomo simples, da física clássica, foi descartado. Por meio da teoria da relatividade geral o observador foi reintroduzido no processo. Há, portanto, a necessidade de se informar qual o referencial utilizado quando se faz uma determinada descrição de um evento observado. A crença de que o mundo era um simples quebra cabeças a ser resolvido, ou, uma máquina com leis precisas de funcionamento a serem desvendadas, está, lentamente, sendo abandonada.

Sabemos hoje, que existem diferentes maneiras de se representar à natureza. Portanto, os fenômenos são alterados quando estudados. O pesquisador se envolve e interpreta os fenômenos a ele submetidos. A observação do cientista tornou-se muito mais complexa do que a visão simplista da física newtoniana fazia supor. Entretanto, "visão complexa" não significa que esta seja mais difícil e complicada. Existem muitas formas de se definir a complexidade dentro da física, mas aqui nós a relacionamos ao tamanho da descrição, isto é, quanto mais extensa a descrição de um evento, tanto mais complexo ele será.

Em muitas áreas, a ciência começa a deparar-se com a aleatoriedade e o paradoxo. 0 que antes era descartado como uma variável "desprezível", começa a ser reavaliado como fator fundamental no processo de funcionamento de diversos sistemas. O observador, sendo uma destas variáveis, não pode mais ser alijado do processo de observação.

\section{A gestão da informação e a complexi- dade dos sistemas de informação}

A Gestão da Informação é uma das seis áreas prioritárias nos currículos dos Cursos de Biblioteconomia e Ciência da Informação dos países do Mercosul. Tem por objetivo geral "capacitar os estudantes na gestão competente, para atuar em sistemas e unidades de informação e em todo tipo de organizações e contextos, com atitude proativa". Como objetivos específicos da área estão o "ser capaz de planejar, implementar, dirigir, coordenar e avaliar sistemas e unidades de informação com visão estratégica". (ACUERDOS..., 1998, p.16). Ponjuán Dante (1998, p.135), conceitua a Gestão da Informação: "Gestión de Información es todo lo relacionado com la obtención de la información adecuada, en la forma correcta, para la persona indicada, ao costo adecuado, en el tiempo oportuno, en el lugar apropriado, para tomar la acción correcta". Por este conceito, podemos perceber que o escopo da Gestão da Informação é bem diferenciado do da Biblioteconomia, principalmente, no tocante à lógica subjacente das funções; isto é, enquanto a lógica da Biblioteconomia é a da demanda, a da Gestão da Informação é a da oferta de produtos e serviços altamente especializados e de valor agregado.

Portanto, são exigidas dos profissionais da informação, em sentido lato, e dos gestores 
de informação, em sentido restrito, algumas competências importantes para o exercício de suas funções, tais como: noções de Administração, Planejamento, Marketing e Negócios.

Com efeito, é no seio dessa discussão que a Teoria do Caos passa a ser um assunto de extrema importância a esses profissionais. Infelizmente, somente uma escola brasileira da área trabalha a Teoria do Caos como um dos conteúdos básicos (fundamentos) do currículo. Trata-se da Universidade do Rio de Janeiro (UNI-RIO), que participou do Diagnóstico Docente da Área 5 - Gestão da Informação, realizado pelas professoras Célia Regina Simonetti Barbalho Coordenadora da Região Norte da Associação Brasileira de Educação em Ciência da Informação (ABECIN) e Margarita de Jesus Escobar de Morel (Universidad Nacional de Asunción) (ASSOCIAÇÃO..., 2003, p.28). Entendemos que administrar a informação nos dias de hoje, é fugir dos "determinismos clássicos", dos arquétipos, dos modelos tradicionais de gerência.

O estudo e a prática dos Sistemas de Informação, desde o seu planejamento até à sua implementação, requer novas maneiras "não-lineares" de concebê-los, levando-se em conta, porém, que "as condições iniciais são relevantes para a previsão de um momento futuro". (ARTONI, 2003, p.24). Ou seja, "a teoria do caos lida com a idéia de que não importa quão boa seja nossa observação dos fatos, sempre haverá erro", diz Celso Grebogi, professor do Departamento de Física Aplicada da Universidade de São Paulo (USP) e um dos pioneiros do estudo do caos no país (ARTONI, 2003, p.27).

Um exemplo clássico do comportamento imprevisível de um sistema caótico são os fractais. Para Artoni (2003, p.27), fractais:

[...] são gráficos matemáticos, gerados por computador, que mostram como pequenas alterações em um traço podem mudar radicalmente o curso do desenho. Esses modelos represen- tam o acaso que, muitas vezes, modifica o destino de algo que deveria ser totalmente determinado por equações matemáticas.

A artista plástica Ostrower, quando se refere às imagens do computador, questiona-se se as mesmas são obras de arte, pois para ela, a exemplo dos fractais, são bonitas, mas não dizem nada sobre nós. São inexpressivos. Não possuem escalas.
Assim, qualquer detalhe, qualquer pontinho (que representa o resultado de cálculos complexos) poderá ser ampliado para qualquer tamanho - e sempre mostrará a mesmíssima estrutura. O tamanho em que nós os vemos depende unicamente do "suporte" (que, de fato, apenas é um suporte) dentro dos limites de uma página de livro, ou na tela do compu- tador, ou projetados num telão gigantesco. Nada se modifica em sua configuração e estrutura. Nada se torna expressivo. (OSTROWER, 1999, p.149).

Para a Ostrower (1999, p.151), "[...] os processos criativos na arte são outros, bem distintos - são intuitivos e associativos, tendo por base nossa consciência e afetividade, a percepção de nós mesmos e dos outros, e o nosso saber da vida e da morte". Em suma, as formas artísticas são formas de comunicação, não apenas de expressão!

Outro autor, desta vez, um especialista em Comunicação - García Gutierrez, em interessante artigo publicado no periódico Transinformação, ao se referir ao "objeto fractal", se expressa da seguinte maneira:

Por ejemplo, siguiendo los procedimentos de la fractalidad sería posible descubrir los "atractores" (tendências predecibles o extrãnas) em los comportamientos aleatórios del acceso a la memória, em la elección y asociación de enlaces sensibles 
aunque "caóticos", em las lógicas complejas de las redes, contribuyendo geometricamente a la explicitación de los órdenes y turbulências que sustentan las redes $y$, desde ahí, a la reorientación ética o política de las memórias colectivas. (GARCÍA GUTIERREZ, 2003, p.19).

Percebemos que o foco principal de García Gutierrez é a Teoria do Caos e a Comunicação Humana. Ele nos diz que os seres humanos sempre fixaram suas memórias em uma diversidade crescente de meios. E, hoje, com os "objetos digitais", tem-se uma integração maior que em outros tempos; porém, tem-se também uma dependência da "mediação externa". Ele acredita que a digitalização não promove apenas vantagens, mas desvantagens, também, em relação "aos valores culturais, à liberdade da memória, à hetero construção de identidades e ao controle do cidadão pelo próprio suporte". (GARCÍA GUTIERREZ, 2003, p.8). Pensa que devemos colocar a Pesquisa em Organização do Conhecimento em uma posição, em larga medida pós-epistemológica, na qual a reflexividade e a complexidade devem comandar tanto as diretrizes quanto as ações dos pesquisadores e profissionais. Isso porque a interação da memória não é explicitável, constituindo-se em uma complexa rede de significados aberta para a instabilidade e para a constante readaptação aos "atratores culturais". A construção da "exomemória" é influenciada por preconceitos locais ou globais, dados historicamente por instâncias que se encontram além do alcance dos cidadãos.

Diante dessa perspectiva, os profissionais da informação trabalham com princípios da Organização da Informação para recuperá-la, analisá-la e transformá-la. Se tomarmos a Análise Documentária como objeto de reflexão, perguntaríamos, então, que conceitos e que princípios seriam os seus? Dodebei (2002, p.19) responde-nos a primeira indagação, dizendo que a discussão dos modelos de organização do conhecimento deve acontecer a partir das interfaces dos conceitos de: Conhecimento, Representação, Informação e Memória. Para esta autora, o papel das Linguagens Documentárias é o de metalinguagens na produção de conhecimentos. Para a autora, as "memórias documentárias" são constructus do conhecimento gerado pela sociedade.

Quanto aos princípios, Silva, Vieira e Silva (2003, p.23) acreditam que há duas condições básicas para que um princípio supere a fase de tentativa e se torne "amplamente aceito:

a) o objetivo deve ser considerado viável pelo consenso profissional; b) deve ser considerado útil. Portanto, entre os vários princípios e convenções aceitos na atualidade, os princípios da Análise Documentária podem ser definidos a partir da seguinte premissa básica, o Princípio geral dos sistemas de recuperação da informação (SRI): Possibilitar a seu usuário o acesso à informação/documentos/memória. E, para que assim seja, a metarepresentação ou representação documentária é explicitada pelos modelos do Ciclo de vida da informação e do sistema de recuperação da informação (SRI). (DODEBEI, 2002, p.37, 43).

Falar em modelos em Ciência da Informação e, por extensão, em Gestão da Informação, equivale a pensar em paradigmas. Há paradigmas ecológicos, locacionais/geográficos, morfológicos, antropológicos/etnológicos, evolucionistas e sistêmicos, entre outros (DODEBEI, 2002, p.21). Como observa Clarke (1972, p.20), a existência de um modelo pressupõe a existência de uma teoria subjacente. Para Clarke, há os seguintes tipos de modelos: físicos/concretos; ou mentais/lógicos. Dentre os primeiros, destacam-se os modelos em escala real ou reduzida, os dinâmicos ou os estáticos. Dentre os segundos, deve-se mencionar os mais importantes: os modelos lógico-conceituais, os matemáticos e estatís- 
ticos, os gráficos, os sistêmicos, os semânticos e as simulações por computador (DODEBEI, 2002, p.20).

Em Ciência da Informação, o paradigma sistêmico, derivado da "Teoria Geral dos Sistemas" de Bertalanffy (1973) é, ao que parece, o mais empregado (DODEBEI, 2002, p.21). A Teoria Geral dos Sistemas (TGS) de Bertalanffy se fundamenta nas seguintes premissas: a) os sistemas existem dentro dos sistemas; b) os sistemas são abertos; c) e as funções de um sistema dependem de sua estrutura (REZENDE; ABREU, 2000, p.28). Esse pensamento exerceu significativa influência na Administração, favorecendo o que se denominou "abordagem sistêmica", representativa da organização em sua totalidade, com seus recursos e seu meio ambiente interno e externo (REZENDE; ABREU, 2000 , p.28). Além disso, sabemos que o pensamento sistêmico, na área organizacional, é compreendido através de um "pensamento linear", o qual pressupõe relações de causa-efeito pré-estabelecidas para os acontecimentos. Segundo Monteiro (2002, p.4) "Nos sistemas organizacionais, por exemplo, uma decisão para um problema é tomada avaliando-se apenas as causas visíveis e diretamente ligadas a ele". Trata-se da "metáfora do iceberg", que compreende os eventos (acima do nível do mar), mas não entende os padrões de comportamento, a estrutura sistêmica, nem os modelos mentais (abaixo do nível do mar) (MONTEIRO, 2002, p.4). Os princípios desta técnica organizacional vêm da obra A Quinta Disciplina, de Peter Senge, do Massachusetts Institute of Technology (MIT), baseada nos estudos de modelos de aprendizagem organizacionais (MONTEIRO, 2002, p.4). Enfim, esta técnica ajuda as empresas/organizações a compreenderem a essência das relações dos sistemas.

No entanto, outras abordagens também são interessantes para os profissionais da informação. São elas, por exemplo: a Abordagem Ecológica de Davenport e Prusak (1998), bastan- te conhecida, e a Abordagem Sociotécnica dos sistemas de Laudon e Laudon (1999). Nesta última, os sistemas devem resolver problemas para os quais eles são projetados como soluções. Para Rezende e Abreu (2000, p.31) "os sistemas podem ser compostos por diversas partes, tais como hardware, software, dados e pessoas, constituindo-se de uma parte técnica e outra social. Por isso, os sistemas requerem investimentos substanciais de ordem social, organizacional e intelectual para funcionarem apropriadamente". É importante que os planejadores de sistemas considerem os objetivos de gestão e o processo decisório, bem como o impacto que estes sistemas terão sobre as pessoas e sobre o contexto organizacional.

Dentro da perspectiva sociotécnica, então, tecnologia e organização (ou empresa) devem ser ajustadas entre si até que se obtenha uma harmonização perfeita entre os dois domínios. Essa harmonia dá-se a partir das diversas alternativas de ambos os lados, para chegar-se a um design final da tecnologia e da organização. (REZENDE; ABREU, 2000, p.31).

Parece-nos bastante simpática a idéia de se trabalhar com as organizações, segundo a perspectiva sociotécnica e o pensamento complexo. Inclusive, na literatura pesquisada, identificamos apenas dois trabalhos, versando sobre essa relação entre Inovação e Estratégias à luz da Teoria da Complexidade (REBELO; ERDMANN, 2004) e Teoria da Complexidade, Inovação e Abordagem Sociotécnica (DUDZIAK, 2004). Daí, então, propormos neste artigo, discutir as implicações de aplicar-se o pensamento complexo ao estudo e formulação de Sistemas de Informação (SI) para as organizações e para os processos de inovação, segundo essa perspectiva sociotécnica. Pressupomos que a adoção desse referencial possibilitará a compreensão de que "a inovação é essencialmente um processo complexo e sociotécnico que se liga mais positivamente a ambientes turbulentos e incertos". (DUDZIAK, 2004, p.190). 
E que, "a não-linearidade, que é inerente aos processos de aprendizado, assim como a causalidade recursiva, são diferentes aspectos da complexidade aplicada às organizações". (DUDZIAK, 2004, p.190).

Portanto, este tipo de abordagem encontra maior respaldo na gestão por processos, tal é o caso, também, da Gestão da Informação. $O$ objetivo deste artigo é mostrar que os SI raramente se parecem com os sistemas analítico-racionais constantes da literatura técnico-organizacional; ou seja, em sua formulação não devemos separar as etapas de planejar e executar. Portanto, defendemos a idéia de que a abordagem da complexidade é uma importante metodologia de análise em estudos que buscam a compreensão de fenômenos sociotécnicos, podendo ser aplicada ao estudo dos processos de inovação organizacional. Nossa hipótese, então, é a de que se os sistemas são sensíveis às condições iniciais, então, estamos frente a um sistema potencialmente caótico. E isto é muito bom.

Outro modelo, amplamente difundido na área ao longo dos anos, foi o de Shannon e Weaver (1963); estes autores propuseram um modelo matemático para explicar a comunicação entre dois pólos - o emissor e o receptor (modelo sistêmico). Trata-se da Teoria Matemática da Informação (TMI) ou Teoria da Informação ou ainda, Teoria da Transmissão de Sinais. Estes autores trabalharam com uma "concepção quantificada da informação, que substitui a linguagem ordinária pelas equações matemáticas, sem aludir ao significado ligado à informação". (MACHADO, 2003, p.12). Wiener, inclusive, definiu claramente o termo: "Informação é informação, nem matéria, nem energia”. Entretanto, para Machado (2003, p.127), a natureza deve ser interpretada como "matéria, energia e informação" (p.24). Como não é possível prever se a informação vai gerar ou não mais informação útil, ela pode ser entendida como uma probabilidade, uma incerteza. E é justamente essa a proposta da TMI: a informação depende de um processo de comunicação entre emissor-canal-receptor, podendo ser quantificada. Aliado a esse pensamento, temos o conceito de informação-potencial de Gilda Braga (MACHADO, 2003, p.11). Este conceito tem justamente como características, as seguintes: a) imprevisibilidade; b) incerteza; c) probabilidade, o que vai de encontro à TMI e está ligado à informação recuperada por meio dos Sistemas de Controle Bibliográfico. Portanto, está ligado também, às duas leis da Cibernética: a) regulação; b) controle. No entanto, Machado (2003, p.27) acredita que "Não é a informaçãopotencial que determina a qualidade da possível informação a ser produzida, mas a relação e a interpretação que aquele que a gera estabelece com os registros recuperados". Ou ainda,

Não são os dados ou conhecimentos que determinam a qualidade da informação, senão a forma como ela é relacionada e interpretada para se adequar a um propósito estabelecido. Assim, a capacidade de gerar informação não depende, de forma exclusiva, dos registros aos quais temos acesso, mas do amadurecimento e do desenvolvimento de habilidades individuais para a manipulação. (MACHADO, 2003, p.21).

Concordamos com Machado (2003, p.36), principalmente, quando temos de efetuar buscas no "caos" da Internet. Para esta autora, asseguram Lawrence e Giles (1999) e Bueno e Vidotti (2000) que as ferramentas de busca alcançam no máximo $16 \%$ da coleção registrada na Internet, em detrimento dos $84 \%$, em razão das limitações técnicas que envolvem o desempenho de cada ferramenta. $\mathrm{Na}$ literatura relativa ao assunto, não há indicação de uma ferramenta de busca ideal. Na decisão por uma delas, devem-se considerar a temática em questão, a expectativa de retorno e ainda o escopo da investigação. Pode-se também utilizar mais de uma 
ferramenta para realizar a mesma pesquisa.

Além deste exemplo, podemos citar a Lei dos 80/20 enunciada por Trueswell (1969) e os comportamentos eleitorais, como outros exemplos de certas classes de fenômenos que apresentam uma regularidade, nas quais um pequeno erro inicial introduz um pequeno erro no resultado. O curso dos eventos nesses casos é considerado estável. Porém, outras classes de fenômenos tornam-se sensíveis às perturbações iniciais, mesmo que sejam aparentemente insignificantes. Aesse respeito, o exemplo maior é o dos Sistemas de Recuperação da Informação, onde

[...] pequenas alterações em uma política de seleção de documentos ou de indexação de descritores, atividades características das condições iniciais desse processo, provocam grandes alterações na recuperação da informação-potencial. Ou ainda, uma estratégia de busca mal estruturada, como uma palavra grafada erroneamente (descrição/discrição), pode recuperar referências indesejáveis e irrelevantes. (MACHADO, 2003, p.36).

Em resumo, a Ciência da Informação absorve ou "importa" numerosos gêneros de modelos que, de ângulos distintos, descrevem a sua realidade. A Ciência da Informação pode ser caracteriza como uma ciência multiparadigmática (DODEBEI, 2002, p.24). Um excelente roteiro pode ser encontrado em Planejamento Estratégico de Sistemas de Informação (PESI) de Furlan (1991), que analisa aspectos da área de negócios, tais como o mapeamento das entidades de recursos de informação, e outros itens.

\section{Caos, informação e negócios}

Em um mundo em constante mudança, o planejamento deve ser realizado de modo a levar em consideração esse aspecto. Isso nos leva a imaginar um planejamento que se adapte às mudanças. Assim, é necessário compreender as interconexões do sistema (fornecedores, clientes, tecnologia, aspectos legais, etc.) para compreender a dinâmica de seu funcionamento. Um exemplo dessa visão de negócio como um sistema e, principalmente, como um ecossistema, é a Cornelia Street, em Greenwich Village, New York (LEWIN; REGINE, 1999).

A rua é composta por pequenos restaurantes. Formada em um bairro que estava em decadência, voltou a atrair intelectuais e artistas com a abertura do Cornelia Street Café em 1977. Aos poucos, a rua foi se enchendo de pequenos restaurantes, cada qual com seu estilo. No entanto, a esperada concorrência não aconteceu. Localizada próxima a tradicionais fornecedores de alimentos, floresceu oferecendo variados tipos de comida: americana, italiana, marroquina, cubana e francesa. Cada um sabe que o cliente pode, e deve, variar o seu cardápio. Assim, não há concorrência. $O$ respeito à opção de cada cliente é estimulado. Paralelamente, a troca de informações, entre os restaurantes, sobre os melhores fornecedores e os tipos de comida disponíveis é uma constante, o que faz com que todos colaborem no sentido de oferecer um ambiente simples e agradável aos clientes. A comunidade de restaurantes então, evoluiu como se fosse um único organismo. Todos acabam se beneficiando dessa sinergia. O desenvolvimento planejado envolve todos os restaurantes e faz com que a comunidade se desenvolva de forma harmoniosa.

Outro exemplo de planejamento adaptável às mudanças pode ser encontrado na escola de samba Imperatriz Leopoldinense (FONTANA; VERGARA, 2001). Os preparativos para o carnaval começam com a carnavalesca elaborando os croquis das fantasias, adereços e bonecos que irão compor a escola, segundo uma idéia geral previamente concebida. São, na realidade, 
esboços que serão desenvolvidos pelos operários. Através do exercício da criatividade de todos os envolvidos chega-se à configuração final do "carnaval" da escola. Essa troca de informações e idéias é feita pelos operários dentro do barracão e especialmente na sala da carnavalesca que está sempre aberta para todos, inclusive para um lanche entre as refeições servidas pela escola. É ali que as pessoas se encontram, trocam idéias e solucionam problemas. A carnavalesca, no entanto, não fica somente em sua sala. Ela circula por todo o barracão dando e recebendo sugestões a respeito do trabalho. Assim, ela consegue uma maior sinergia entre todos os envolvidos e vai tornando realidade a imagem que a escola mostrará na avenida. É um processo em que o resultado final só será conhecido poucas horas antes da escola entrar na avenida.

\section{CONSIDERAÇÕ ES FINAIS}

De acordo com Prigogine (1991), uma das habilidades mais refinadas no Ocidente é o processo de dissecar, de reduzir os problemas a componentes simples. Ele afirma que o conhecimento produzido pela ciência mecânica e reducionista nos levou a modelos e teorias que se tornaram pragmáticas. A teoria de sistemas caóticos oferece uma nova abordagem de orientação ao processo, em contrapartida às abordagens de orientação ao objeto, da visão clássica.

A análise de sistemas caóticos está se tornando um método importante de pesquisas nas ciências biológicas e do comportamento. $A$ metodologia do caos transferiu a ênfase nas relações de causa e efeito para abordagens que enfatizam a importância de definição de padrões, formas, organização, e as qualidades adaptativas dos processos complexos. A análise de sistemas caóticos nos fornece uma maneira rica para descrevermos o mundo e seus fenômenos. Qualquer pesquisa científica é uma narrativa que pode fornecer informações úteis para o nosso entendimento do mundo.

Assim, o planejamento de sistemas de informação deveria se apoiar no que Edgar Morin (1989, p.13) chamou de "Método da Complexidade". Este método não busca nem a certeza, nem a verdade única. É a "busca de um modo de pensamento capaz de respeitar a multidimensionalidade, a riqueza, o mistério real; e saber que as determinações - cerebral, cultural, social, histórica - que se impõem a todo o pensamento co-determinam sempre o objeto de conhecimento". (MORIN, 1989, p.14).

A partir de todo esse arcabouço conceitual, queremos defender a tese de que os profissionais da informação têm de atentar sobremaneira à fase de planejamento dos Sistemas de Informação, antes mesmo de sua administração, porque, como já foi dito neste artigo "a teoria do caos lida com a idéia de que não importa quão boa seja nossa observação dos fatos, sempre haverá erro" ou que devemos levar em conta que "as condições iniciais são relevantes para a previsão de um momento futuro". Ou seja, para um correto e eficiente gerenciamento estratégico de sistemas de informação, é imprescindível, ao mesmo, o seu planejamento. Sem que isto ocorra, fica extremamente difícil democratizar o acesso às informações nas organizações.

Hoje, a Gestão da Informação é uma arma estratégica para a competitividade global, pois as pessoas com as novas tecnologias de informação geram resultados melhores; a informatização com reengenharia produz eficácia e a democratização das informações conduzem a uma maior agilidade para os negócios. Daí, a Gestão da Informação ser vista como estratégica, ao mesmo tempo em que dá maior poder de decisão para as pessoas.

Enfim, para a Teoria do Caos, a previsão nem sempre é possível, ao passo que, para a Gestão da Informação, ou melhor, para os Sistemas de Informação, o seu planejamento, é 
imprescindível, porém, desvinculado da noção de que documento é igual à informação, porque com o advento das tecnologias de informação e comunicação (TIC), que procuram se apropriar do pensamento humano (associação), as

\section{REFER Ê N CIAS}

ASSOCIAÇÃO BRASILEIRA DE EDUCAÇÃO EM CIÊNCIA DA INFORMAÇÃO. SEMINÁRIO PEDAGÓGICO ABECIN: Gestão da Informação, 1., 2003, Belo Horizonte. Anais... Belo Horizonte: Escola de Ciência da Informação da UFMG, 2003. 50p.

ACUERDOS y recomendaciones. In: ENCUENTRO DE DIRECTORES Y DE DOCENTES DE ESCUELAS DE BIBLIOTECOLOGÍA Y CIENCIA DE LA INFORMACIÓN DEL MERCOSUR, 3., Santiago de Chile, 1998. Anais... Santiago: UTEM, 1998. 182p.

ARTONI, C. Lei de Murphy: quando tudo dá errado. Galileu, São Paulo, p.20-27, 2003.

BERTALANFFY, L. Von. Teoria general de los sistemas: fundamentos, desarrollo, aplicaciones. Mejico: Fondo de Cultura Económica, 1973.

BOHM, D. A totalidade e a ordem implicada. São Paulo: Cultrix, 1992.

BUENO, M.C.; VIDOTTI, S.A.B.G. Ferramentas de busca na Internet: para quê, por quê e como utilizálas? In: SIMPÓSIO NACIONAL DE BIBLIOTECAS UNIVERSITÁRIAS, 2000. Anais... Florianópolis, 2000. CD-ROM.

CLARKE, D. Models in Archaeology. London: Methuen, 1972.

DAVENPORT, T.H.; PRUSAK, L. Ecologia da informação: por que só a tecnologia não basta para o sucesso na era da informação. São Paulo: Futura, 1998.

DODEBEI, V.L.D. Tesauro: linguagem de representação da memória documentária. Rio de Janeiro: Interciência, 2002.

DUDZIAK, E. A Teoria da complexidade e o estudo da inovação nas organizações: subsídios a uma abordagem sociotécnica. In: SIMPÓSIO DE GESTÃO DA INOVAÇÃO TECNOLÓGICA, 23., Curitiba, 2004. Anais... Curitiba: TECPAR, 2004. p.4404-4416.

FIEDLER-FERRARA, N.; PRADO, C.P.C. Caos: uma introdução. São Paulo: Edgar Blücher, 1994. relações têm de ser "caóticas"; não podem ser tão somente "lineares". Logo, deve-se rever a entropia dos Sistemas de Recuperação da Informação (SRI) e novos estudos deverão ser realizados a respeito.

FONTANA, A.; VERGARA, S.C. A vitória da (des)organização. VOCÊ SA, p.70-73, abr. 2001.

FURLAN, J.D. Análise de negócio e diagnóstico situacional. In: FURLAN, J.D. Como elaborar e implementar o planejamento estratégico de sistemas de informação. São Paulo: Makron Books, 1991. p.16-55.

GARCÍA GUTIERREZ, A. Proyectar la memória: del ordo nacional a la reapropiación crítica. Transinformação, Campinas, v.15, n.1, p.7-30, 2003.

GLEICK, J. Caos: a criação de uma nova ciência. 2.ed. Rio de Janeiro: Campus, 1990.

HEISENBERG, W. Física e filosofia. 2.ed. Brasília: Editora UnB, 1987.

LAUDON, K.C.; LAUDON, J.P. Sistemas de informação. 4.ed. Rio de Janeiro: LTC, 1999.

LEWIN, R. Complexidade: a vida no limite do caos. Rio de Janeiro: Rocco, 1994.

LEWIN, R.; REGINE, B. The soul at work. London: Orion Business, 1999.

LORENZ, E.N. A essência do caos. Brasília: Editora UnB, 1996.

MACHADO, A.M.N. Informação e controle bibliográfico: um olhar sobre a cibernética. São Paulo: Unesp, 2003.

MONTEIRO, A.L. Pensamento sistêmico nas organizações. InoveAção, Curitiba, v.1, n.3, p.4, 2002.

MORIN, E. O método Il: a vida da vida. 2. ed. Lisboa: Europa-América, 1989.

OSTROWER, F. Arte sobre papel: da gravura chinesa às imagens do computador. In: DOCTORS, M. (Org.). A cultura do papel. Rio de Janeiro: Casa da Palavra: Fundação Eva Klabin Rapaport, 1999. p.123-184.

PONJUÁN DANTE, G. Gestión de información en las organizaciones: principios, conceptos y 
aplicaciones. [s.I.]: CECAPI/Universidad de Chile, 1998.

PRIGOGINE, I.; STENGERS, I. A nova aliança. Brasília: Editora Unb, 1991.

REBELO, L.M.B.; ERDMANN, R.H. Proposta de inovação na gestão universitária: formação de estratégias à luz da Teoria da Complexidade. In: SIMPÓSIO DE GESTÃO DA INOVAÇÃO TECNOLÓGICA, 23., Curitiba, 2004. Anais... Curitiba: TECPAR, 2004. p.4374-4389.

REZENDE, D.A.; ABREU, A.F. Tecnologia da informação aplicada a sistemas de informação empresariais: o papel estratégico da informação e dos sistemas de informação nas empresas. São Paulo: Atlas, 2000.

SCHUSTER, H.G. Deterministic chaos: an introduction. Weinheim: VCH, 1995.

SHANNON, C.E.; WEAWER, W. The mathemathical theory of communication. Urbana: The University of Illinois Press, 1963.

SILVA, C.A.S.; VIEIRA, C.; SILVA, R.N.S. Contabilidade para executivos. Rio de Janeiro: FGV, 2003. p.23-24.

TRUESWELL, R.L. Some behavioral patterns of library users: the $80 / 20$ rule. Wilson Library Bulletin, v.23, n.5, p.458-461, 1969. 
